\title{
An embryological point of view on associated congenital anomalies of children with Hirschsprung disease
}

\author{
Slavikova $\mathrm{T}^{1}$, Zabojnikova $\mathrm{L}^{2}$, Babala $\mathrm{J}^{2}$, Varga $\mathrm{I}^{1}$ \\ Institute of Histology and Embryology, Faculty of Medicine, Comenius University in Bratislava, Slovakia. \\ ivan.varga@fmed.uniba.sk
}

\begin{abstract}
The most common congenital gut motility disorder is the Hirschsprung disease (HSCR). This anomaly is characterized by absence of neural crest-derived enteric neuronal ganglia. The aim of our study was to analyze the relationship between HSCR and other congenital anomalies or malfunctions. We examined 130 patients with Hirschsprung disease from Slovakia for last 10 years. During patients examination we focused not only on morphological abnormalities, but also functional anomalies. The incidence of associated congenital anomalies in our patients with HSCR was $26.1 \%$. But if we add functional defects (hypothyroidism, malfunction in cellular immunity, neurological deficit) to the morphological congenital abnormalities, the rate of the patients with HSCR with additional defects achieves $50.1 \%$. Nine of our patients $(6.9 \%)$ had syndromic HSCR. The most frequent disorder (13.6\% of patients) was primary deficiency in cellular immunity. More than $12.3 \%$ of patients with HSCR had genitourinary abnormalities, in $10.0 \%$ of patients variable degree of psychomotor retardation was observed, and skeletal, muscle and limb anomalies involved $7.7 \%$ of patients. In $7.6 \%$ cases of patients we found congenital hypothyroidism (including 2 cases of agenesis of thyroid gland). More than $6.1 \%$ of patients presented with an associated anomaly in gastrointestinal tract (mostly anorectal malformations). Up to $5.5 \%$ patients had congenital anomaly of heart, 3.8 \% had ophthalmic and 3.1\% had craniofacial anomalies. Down syndrome was the main diagnosis in $3.8 \%$ patients. We discussed the relationship between HSCR and other anomalies, which are probably caused by abnormal migration, proliferation, or differentiation, of neural crest cells during embryogenesis (Tab. 1, Fig. 2, Ref. 75). Text in PDF www.elis.sk.

KEY WORDS: Hirschsprung disease, impaired cellular immunity, genitourinary abnormalities, neurological deficiency, hypothyroidism, cardiac abnormalities, Down syndrome.
\end{abstract}

\section{Introduction}

Hirschsprung disease (HSCR) is the most common congenital gut motility disorder and is characterized by a lack of nerve cells (aganglionosis) in a variable length of distal gut (1). Usually this involves just a short segment, the rectum and sigmoid colon, but occasionally there is much greater involvement of the colon and, even more rarely, involvement extending to the ileum. The functional characteristic of the disease is intestinal obstruction, caused by the localized inability of the gut to transmit a peristaltic wave; this section of the bowel is typically contracted. In contrast, the segment of intestine proximal to this becomes grossly distended by fecal accumulation, and this is termed as "megacolon" (2).

Gut motility is a complex process mediated by interactions between smooth muscle cells, interstitial cells of Cajal with pacemaker-activity (generation of slow electrical waves that underlie

${ }^{1}$ Institute of Histology and Embryology, Faculty of Medicine, Comenius University in Bratislava, Slovakia, and ${ }^{2}$ Department of Pediatric Surgery, Faculty of Medicine and Children's Medical Hospital, Comenius University in Bratislava, Slovakia

Address for correspondence: I. Varga, RND, PhD, Institute of Histology and Embryology, Faculty of Medicine, Comenius University in Bratislava, Sasinkova 4, SK-811 08 Bratislava, Slovakia.

Phone: +421.2 .59357547$ rhythmic contractions), and the neurons of enteric nervous system (ENS). One part of ENS is localized in the layer of connective tissue of tela submucosa (submucosal Meissner plexus), and the second part lies between circular and longitudinal layers of tunica muscularis (myenteric Auerbach plexus). The submucosal plexus regulates mostly the intestinal secretory function, whereas the myenteric plexus regulates the dilatation and contraction of the intestinal wall (3). From an embryological point of view, smooth muscle and interstitial cells of Cajal are derived from embryonic mesenchyme, but precursors of neurons and supporting glial cells of ENS are of neural crest origin (4).

The neural crest is a transient paired embryonic structure that gives rise to more than fifty cell types and tissues of adults, ranging from neurons of enteric nervous system to the facial connective tissue and skeleton (5-7). Neural crest cells originate in the dorsal parts of neural folds of developing neural tube, at the junction between neural ectoderm (the neural plate as the future brain and spinal cord) and non-neural ectoderm (future epidermis of the skin) (8). During the development of neural tube, the cells of neural crest origin underwent epithelial-to-mesenchymal transition (9) and migrate via different pathways into the whole embryo. They give rise to e.g., neuronal and supporting glia of peripheral (including autonomic and enteric) nervous system, pigment cells, chromaffin cells of adrenal medulla and paraganglia, and dentine-producing 
odontoblasts of teeth $(7,10,11)$. In the cranial parts of embryo, the neural crest cells differentiate also into mesenchyme and are source of cells for future connective and muscle tissues inside embryonic pharyngeal arches. Therefore the neural crest cells are extremely important for normal development of the face, ventral neck, parathyroid glands, thyroid gland and thymus $(12,13)$. Neural crest cells play also important role in the development of the heart, especially during outflow tract septation (future ascending aorta and pulmonary trunk, conus arteriosus and aortic vestibule), valvulogenesis, and development of the cardiac conduction system $(14,15)$. The neural crest is a fascinating embryonic structure and for its important role during normal development of various organs some authors term it as "the fourth embryonic germ layer" (16).

The aim of our study was to analyze the relationship between Hirschsprung disease and other congenital anomalies, which are probably caused by abnormal migration, proliferation, differentiation, or survival of neural crest cells during embryonic development. We examined patients with Hirschsprung disease from Slovakia for last 10 years and discussed about a possible embryonic basis of co-existence of different congenital anomalies and malfunctions.

\section{Patients and methods}

We analyzed retrospectively 130 pediatric patients from Department of Pediatric Surgery, Faculty of Medicine and Children's Medical Hospital in Bratislava, Slovakia. All patients underwent surgical procedure during years 2002-2012. The majority of patients were term babies and their birth weights were between 2500 $\mathrm{g}$ and $3500 \mathrm{~g}$. Male-to-female ratio was 1.6 to 1 . In 5 patients (3.85 $\%$ ) we found also HSCR disease among their family members (siblings or parents).

Conventional or classic approach was used including two or three-stage operative procedures. In the first stage laparotomy (in last years also laparoscopy), abdominal inspection, bowel biopsies and colostomy were done. The second stage, performed later, usually after three months to one year of age, included resection of aganglionated bowel and colon-anal anastomosis. The preexisting stoma could be closed at this operation or during the third-stage procedure. The most common surgical procedure in our series of patients was the retro-rectal pull-through according to Duhamel

Tab. 1. Related congenital anomalies and malfunctions in patients with HSCR.

\begin{tabular}{lcc}
\hline Description of congenital anomaly & Percentage & $\begin{array}{c}\text { No of } \\
\text { patients }\end{array}$ \\
\hline Deficiency in cellular immunity & $13.6 \%$ & 18 \\
Genitourinary abnormalities & $12.3 \%$ & 16 \\
Neurological or psychomotor deficiency & $10.0 \%$ & 13 \\
Skeletal, muscle and limb anomalies & $7.7 \%$ & 10 \\
Congenital hypothyroidism/agenesis of thyroid gland & $7.6 \%$ & 9 \\
Other gastrointestinal tract anomalies & $6.1 \%$ & 8 \\
Congenital heart defects, cardiac abnormalities & $5.3 \%$ & 7 \\
Down syndrome & $3.8 \%$ & 5 \\
Ophthalmic anomalies & $3.8 \%$ & 5 \\
Craniofacial anomalies & $3.1 \%$ & 4 \\
CNS and brain anomalies & $2.3 \%$ & 3 \\
\hline
\end{tabular}

(17) in Ikeda - Soper's modification $(18,19)$. The mean age of patients during the first operation was 350 days, and most of the patients underwent another on operation, average 2.56 re-operations of abdomen.

The diagnosis of HSCR was verified histologically and histochemically (lack of acetylcholinesterase-positive ganglion cells and well developed nerve fibers).

During patient examination we focused not only at routinely examined morphologically abnormalities (e.g., abnormal facial features, defects of limbs or skeleton, congenital heart defects), but also at morphological and functional anomalies of endocrine (thyroid gland) and immune organs (thymus) and neurological or psychomotor deficiency.

\section{Results}

The incidence of associated congenital anomalies in our patients with Hirschsprung disease was $26.1 \%$ (34 patients). Only $12 \%$ of them had other single anomaly, and $88 \%$ had multiple congenital anomalies. But if we add functional defects (hypothyroidism, malfunction in cellular immunity, neurological deficit) to the morphological congenital abnormalities, the rate of the patients with HSCR with additional defects achieves 50.1\% (66 patients). The list of our results is summarized in Table 1. Nine of our patients (6.9\%) had syndromic HSCR (five cases of Down syndrome, one case of hydrocephalus due to congenital stenosis of the aqueduct of midbrain (of Sylvius), one case of Currarino triad with sacral agenesis, one case of Duchenne muscular dystrophy and one case of cartilage-hair hypoplasia). If we analyzed the gender influence on associated congenital anomalies, no statistical significance was found. In males with Hirschprung disease, $49 \%$ had another concomitant congenital anomaly (39 from 80 male patients), in females $52 \%$ had another congenital anomaly (26 from 50 female patients).

The most frequent disorder (more than $13.6 \%$ of patients) was the deficiency in immune functions, mostly primary deficiency in cellular immunity. These patients are in a long- term follow up of immunologists, due to repeated infections (mostly of viral origin). Despite the fact that they have no severe manifestation of immunodeficiency, the amount of various subpopulations of T- lymphocytes in peripheral blood is in the lower zone of normal values, when examined by flow cytometry. This deficiency is probably due to disturbed development of thymus, and consecutively disturbed development of immunocompetent T- lymphocytes.

More than $12.3 \%$ of patients with HSCR had genitourinary abnormalities, including congenital kidney anomalies (Fig. 1), agenesis of kidney, hydronephrosis / hydroureter, retentio testis and disorders of bladder function.

In $10.0 \%$ of patients variable degree of psychomotor retardation was observed, without any specific morphologic findings with available imaging methods. Most of these patients are in long-term follow-up by neurologist and/or psychologist. Delayed psychomotor development was a common finding in many patients; some of them had problems with speaking and most of them are also in the care of speech therapist (logopaedist), because of dyslalic 


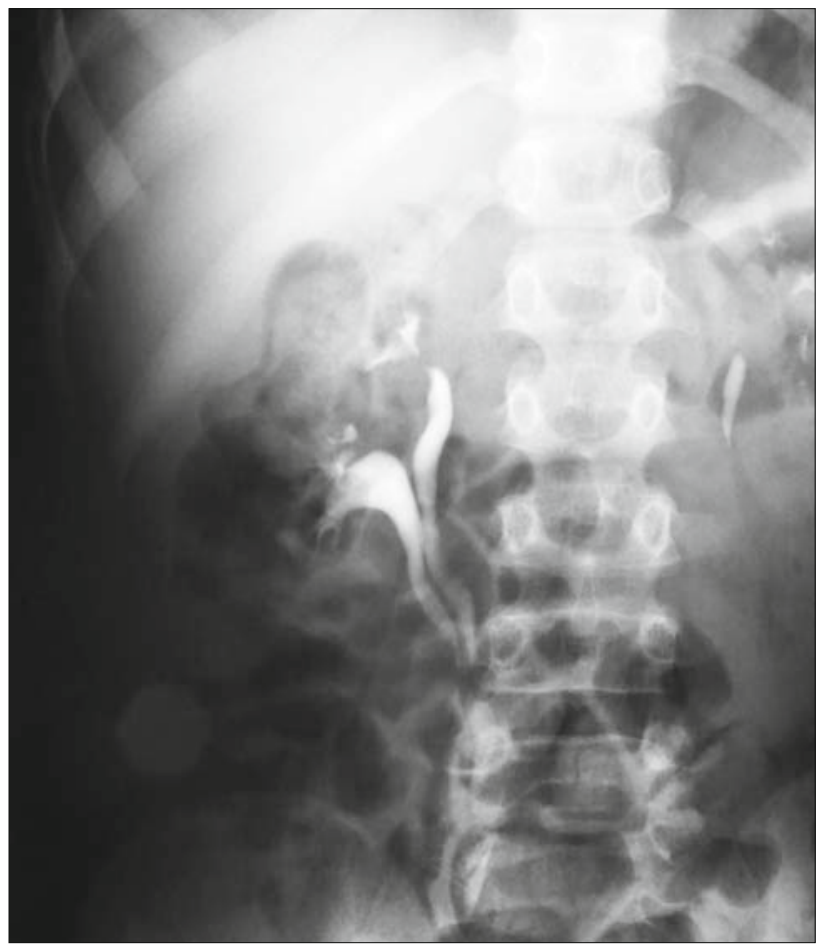

Fig. 1. Six-year-old boy with Hirschsprung disease and concomitant renal anomaly (ren duplex).

speech. Morphological congenital anomaly of central nervous system was found in additional $2.3 \%$ of patients (as spina bifida, meningocoele and hydrocephalus due to congenital stenosis of the aqueduct of midbrain (of Sylvius).

Skeletal, muscle, limb and digital anomalies involve $7.7 \%$ of patients with Hirschsprung disease. This group of anomalies was represented with chondrodystrophy, thoracic kyphosis, pectus excavatum with scoliosis, unilateral phocomelia, sacral agenesis (Fig. 2), Duchenne muscular dystrophy, syndactylia, valgus or varus knee deformities, pedes plani and global muscular hypotonia.

In $7.6 \%$ cases of patients with HSCR we found congenital hypofunction of thyroid gland. In 2 cases $(1.5 \%)$ we found a complete agenesis of thyroid gland.

More than $6.1 \%$ of patients presented with an associated anomaly in gastrointestinal tract along with the hypogangliosis. Atresia of the gastrointestinal tube in various levels (atresia of ileum or atresia of rectum and anus) and gastroschisis were the most common added congenital anomalies to Hirschsprung disease. Other most common gastrointestinal tract anomalies were anorectal malformations ( 3 cases, $2.3 \%$ ).

Up to $5.5 \%$ patients had a congenital anomaly of heart, such as septation defects, ventricular and atrial septal defects and conotruncal developmental defect (exclude patients with concomitant Down syndrome, where the association between Down syndrome and congenital heart defect is well known).

Ophthalmic anomalies (3.8\%) and other craniofacial anomalies (3.1\%) was a morphological finding in patients with multiple diagnoses as a part of complex stigmatization. We found two cases

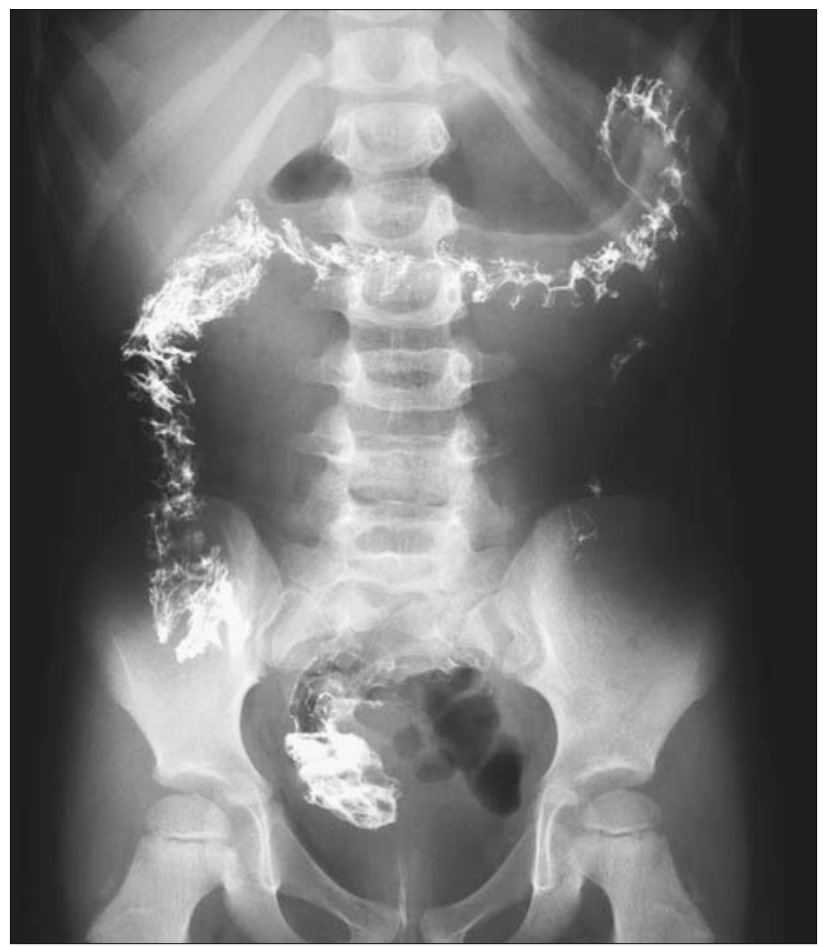

Fig. 2. Six-year-old boy with Hirschsprung disease and concomitant skeletal anomaly (sacral agenesis).

of strabismus convergens, one case of microphthalmia, one case of retinopathy and one case of keratopathy.

Down syndrome, trisomy of chromosome 21 , was the main diagnosis in 5 patients $(3.8 \%)$. Two of these patients had concomitant congenital hypothyroidism, and one had also concomitant congenital heart defect (atrial septal defect).

\section{Discussion}

The first neural crest ablation studies in chick-quail chimaera (transplanted grafts of quail neural primordium into chick embryos) experiments in 1973 have shown that neurons in the wall of gut are derived from the neural crest (20). Neural crest cells undergo extensive migration, proliferation, differentiation and survival during the development of gut to form a functional enteric nervous system. In humans, the first neural crest cells enter the foregut at week 4, and migrate cranio-caudally to reach the terminal hindgut by week 7 . Neural crest cells then differentiate into neurons and glia of future enteric nervous system (4, 21-23). Only a fully colonized developing gut, comprising the appropriate number of diverse neuronal and glial cells types, is required for normal coordinated peristaltic activity. The most common and best understood congenital gut motility disorder is the Hirschsprung disease (according to the Dutch pediatrician Harald Hirschsprung, who described this unit in 1888) (24). HSCR occurs in 1 to 5000 live births. This congenital anomaly is characterized by an absence of enteric neuronal ganglia (aganglionosis) in aboral regions of the gut, leading to tonic contraction of the affected segment, intesti- 
nal obstruction and massive distension of the unaffected proximal bowel $(23,25)$.

HSCR is a complex disease that results from the interaction of several genes and manifests with low, sex-dependent penetrance and variability in the length of the aganglionic segment. The total prevalence of HSCR in Europe between years 1980-2009 was 1.09 per 10,000 births (26). In HSCR is a gender disparity among the patients, with the male to female ratio as high as $5: 1$. Recent studies identified over half of the HSCR disease susceptibility genes as targets for the sex-determining factor SRY, suggesting that this Y-encoded transcription factor could be involved in sexual dimorphism in HSCR (27). In the group of our patients with HSCR the male to female ratio was lower than reported values, and was only 1.6 to 1 . The explanation for this difference may be the fact that most difficult patients from the entire country come to our university clinic, and most of them have the diagnosis of long-segment Hirschsprung disease. According to Amiel et al. (28) the male to female ratio is significantly lower for long-segment HSCR (1.2-1.9) than for short-segment HSCR (4.2-4.4).

Affected families carry 200 times higher risk but genetic counseling via pedigree analysis is difficult and the significance of genetic variations is unclear (29). In our study, we described familial occurrence of HSCR in 5 cases (3.8\%). According to Puri and Shinkai (30), the reported incidence of familial cases in rectosigmoid HSCR varies from $3.6 \%$ to $7.8 \%$. The estimated risk of HSCR transmission to relatives increases with rising extent of aganglionosis (from recurrence of risk $4 \%$ in brothers of patient with rectosigmoid HSCR to $29 \%$ in sons of females with longsegment HSCR) (27). Recently, several genes (at least twelve) have been identified that control morphogenesis and differentiation of the enteric nervous system. These genes, when mutated or deleted, interfere with enteric nervous system development. The most studied are mutations in RET proto-oncogen, which is the major genetic cause of HSCR. The RET signaling pathway is of importance for enteric nervous system development to promote survival of neurons, mitosis of neuronal progenitor cells, differentiation of neurons and nerve fibers extension $(2,30)$. In the neighboring Czech Republic, the occurrence of RET mutation in patients with HSCR is estimated to be $10 \%$ (31).

In our group of patients with HSCR, $26.1 \%$ had associated congenital anomalies. Moore (32) analyzed 4,328 reported cases of HSCR and the incidence of other anomalies varied between 5 and $32 \%$ with a mean of $21.1 \%$. But similar number of our patients had also congenital functional endocrine, immunological or neurological deficit, without morphologically evident anomaly (congenital hypothyroidism, impaired cellular immunity, psychomotor retardation). This means that together more than $50 \%$ of all patients with Hirschsprung disease had another congenital anomaly or congenital impaired endocrine, immunologic or psychomotor functions.

\section{Hirschsprung disease and immune system}

More than $13 \%$ of our patients with HSCR had primary deficit in cellular immunity. We found only one similar article compar- ing immunologic functions and developmental anomalies of large intestine (33). The explanation of immune deficit in patients with HSCR can be in disrupted embryonic development of the thymus. The vagal neural crest cells are the major source of thymic mesenchyme during development, as well as are the major source of neurons and glial future enteric nervous system (34). The interaction between the developing epithelial primordium of thymus derived from the third pharyngeal pouch and surrounding neural crest derived-cells mesenchyme is necessary for the proliferation and differentiation of thymic epithelial cells, and for the differentiation of fully developed lymphoid thymus (35). According to our opinion, the disrupted formation, migration, differentiation or survival of vagal neural crest cells can also disrupt the development of both, the thymus and the enteric nervous system in bowel. The mucosa of bowel full-filled with T- lymphocytes is also an important site of B- lymphocytes development (36). Therefore the disrupted development of large intestine and/or thymus can hypothetically also affect the developing humoral immunity in patients with HSCR.

\section{Hirschsprung disease and genitourinary malformations}

In the group of our patients, the incidence of genitourinary malformations was $12.3 \%$ that is higher than the mean reported incidence, $6.05 \%$ (32). These malformations in HSCR patients can be explained by genetic alterations of RET proto-oncogen. The RET proto-oncogene encodes a receptor tyrosine-kinase which plays a crucial role during the embryonic development of the enteric nervous system and kidney (especially the embryonic mesonephric Wolffian duct and ureteric bud epithelium, which are critical for kidney induction and branching morphogenesis). The importance of RET in mammalian organogenesis has been further illustrated by the generation of RET knock-out mouse. This mouse exhibits total intestinal agangliosis and renal agenesis $(37,38)$. The mean reported incidence of RET proto-oncogen mutations is $70-80 \%$ in cases of long-segment HSCR, $50 \%$ in familial cases of HSCR and $15-20 \%$ of sporadic forms of HSCR $(30,39)$. It is highly probable, that patients with these mutations have higher susceptibility for developmental anomalies of kidney and excretory passages. This hypothesis confirms the study of Skinner et al (40). They found mutations in RET proto-oncogen in cases of bilateral renal agenesis in $37 \%$ of stillborn fetuses and in cases with unilateral renal agenesis in $20 \%$.

\section{Hirschsprung disease and neurologic and psychomotor de- ficiency}

Approximately $10 \%$ of our patients with HSCR were affected by associated neurological or psychomotor challenges. Similar are the results of Moore and Tshifularo (41), who found associated neurological difficulties in $6 \%$ of patients with HSCR (32 from 555 patients). Also Shahar and Shinawi (42) reported about 4 patients with HSCR with associated neurological abnormalities, or Baranyay et al (43) described a case report of adult patient with HSCR and concomitant mental retardation. Most of these neuro- 
logical anomalies may be linked with disrupted migration or differentiation of neural crest cells, mostly in cases of HSCR associated with different syndromes (Goldberg-Shprintzen or Haddad syndrome). But we think that also the number of re-operations, the quality of anesthesia, surgery and post-operative care may affect other psychomotor development of children.

\section{Hirschsprung disease and skeletal, limb and digital anoma- lies}

A wide range of skeletal, muscle, limb and digital anomalies of our patients with HSCR include chondrodystrophy, thoracic kyphosis, pectus excavatum with scoliosis, unilateral phocomelia, sacral agenesis, muscular dystrophy, syndactylia, valgus or varus knee deformities, pedes plani and global muscular hypotonia and constitute $7.7 \%$ of all patients with HSCR. According to Moore (32), who analyzed numerous different studies, the skeletal, muscle and limb anomalies involve approximately $5.12 \%$ of HSCR patients. But in some studies, this percentage can be as high as $24 \%$ (44). Some of our patients had different syndromes, and the skeletal and muscular anomalies were only a part of different abnormalities (e.g., one case of sacral agenesis in a Currarino triad syndrome, chondrodystrophy in a cartilage-hair hypoplasia or Duchenne muscular dystrophy). Our case of Hirschsprung disease associated with Currarino triad (Fig. 2) is extremely rare and according to our knowledge, is it only the third reported case in the literature ever $(45,46)$. Also several other authors described cases of skeletal or limb anomalies in different syndromes associated with Hirschsprung disease. For example, Alkuraya et al (47) reported about a newborn girl with Fryns syndrome (multiple congenital anomalies characterized also by distal limb hypoplasia) associated with HSCR, and Goldenberg et al (48) reported a case of absence of tibiae and polysyndactyly of hands and feet associated with HSCR.

\section{Hirschsprung disease and thyroid function}

The first mention about association between Hirschsprung disease and congenital hypothyroidism originates from Mustafin and Sultanova (49). They described 3 cases of hypothyroidism in a group of 78 HSCR children (3.8\%). In our group of HSCR patients more than $7.6 \%$ suffered from congenital hypothyroidism, and in two cases there was a complete congenital agenesis of the thyroid gland. From animal models it is well known that hypothyroidism impairs colic motility and function (50). But we found only two recent articles (both are case reports) about the association between HSCR and congenital hypothyroidism $(51,52)$ and only one research article about an association between congenital hypothyroidism and different birth defects (including HSCR) (53). The possible association between HSCR and congenital hypothyroidism can be in disturbed migration of neural crest cells in both developing organs, into the thyroid gland and intestine. The vagal neural crest cells are extremely important not only in normal development of enteric nervous system, pharyngeal arches (future face and ventral neck) and heart outflow tract, but also in the develop- ment of the thyroid gland, regulating the formation and migration of thyroid gland (as well as thymus and parathyroid glands). The future connective tissue of thyroid gland (capsule and septa) and the parafollicular calcitonin-producing cells inside thyroid gland are of neural crest origin $(7,13,54)$.

\section{Hirschsprung disease and other gastrointestinal tract anoma-} lies

Similar signaling molecular pathways are implicated in normal development of numerous derivates of primitive gut, the future parts of gastrointestinal system. Therefore, it is not surprising that 6 $\%$ of our HSCR patients who had disrupt development of the enteric nervous system, suffered from other congenital gastrointestinal tract anomaly. Our result was similar to the mean of published data $8.05 \%$ (32). Most frequent anomaly in our patients was anorectal malformation ( 3 cases, $2.3 \%$ ). This finding is in agreement with the reported incidence ( $2.3 \%$ to $3.4 \%$ ) of anorectal malformations in patients with Hirschsprung disease (55). One of the newest surgical procedures in HSCR with non-relaxing anal sphincter is application of intrasphincteric botulinum toxin (Botox). According to Han-Geurts et al (56), the intrasphincteric Botox injections in surgically treated HSCR are an effective long-term therapy in approximately half of our patients with obstructive symptoms.

\section{Hirschsprung disease and congenital heart defects}

Approximately $0.4 \%$ up to $0.6 \%$ of newborns is delivered with moderate or severe congenital heart defects (57). These congenital heart defects are etiologically heterogeneous, and genetic and environmental causes have been proposed for many specific defects (58). In the group of our patients with HSCR, the incidence of congenital heart defects was $5.3 \%$. According to Spouge and Baird (59), the cardiovascular anomalies are one of the most frequent additional anomalies found in HSCR patients, occurring in $5.6 \%$ of cases. Approximately half of HSCR patients with associated congenital heart disease had major heart defect requiring surgical repair (60). The etiology of combined HSCR and heart defects is in the common progenitor neural crest cells important for normogenesis of the heart and enteric nervous system. More than 30 years ago, the first paper showing the relationship of neural crest-cells with heart development was published (61). Multipotent cardiac neural crest cells (a special population of vagal neural crest cells) migrate into the developing heart and become condensed in the aorticopulmonary septation complex (62). Ablation of a smaller area within the cardiac neural crest is thought to contribute to conotruncal anomalies including tetralogy of Fallot and double-outlet right ventricle $(63,64)$. Our patients with HSCR had septation defects of the heart as well conoctruncal anomalies, probably due to disrupted migration of neural crest cells.

\section{Hirschsprung disease and ophthalmic anomalies}

Five (3.8\%) HSCR patients had also ophthalmic anomalies, which is similar to data (2.2\%) published by Moore et al (65). In 
general, some of congenital ophthalmic anomalies belong to the disorders of neural crest origin, e.g. pupil abnormalities and iris dysplasia and can be associated with other neurocristopathies (66). We found in our group of HSCR patients two cases of strabismus convergens. We cannot explain this concomitant occurrence of two anomalies. In literature, we have found only three similar cases, but the strabismus associated with HSCR was only a part of different syndromes and genetic abnormalities (67-69).

\section{Hirschsprung disease and craniofacial abnormalities}

More than $3 \%$ of HSCR patients had associated craniofacial abnormalities. Reported incidence of these anomalies in HSCR patients is $2.86 \%$ (32). Associations between HSCR and craniofacial anomalies are well known. Neural crest cell produces an array of hard and soft connective tissue in the face and head, which elsewhere in the body have a mesodermal origin. Neural crest cells during morphogenesis of craniofacial region involve the same growth factor and signaling pathways as neural crest during development of enteric nervous system (70).

\section{Hirschsprung disease and Down syndrome}

A large number of chromosomal anomalies have been described in HSCR patients. Trisomy 21 (Down syndrome) is by far the most frequent, involving $2-15 \%$ of ascertained HSCR cases $(28,71)$. Individuals with Down syndrome display a $40-$ fold greater risk of Hirschsprung disease than the general population of newborns. In our group of patients with HSCR, 3.8 \% had also concomitant Down syndrome. According to the hypothesis of Arnold et al (72), segregation of a common polymorphism at RET enhancer, residing on human chromosome 10, interacts with chromosome 21 and leads to the Hirschsprung disease association in Down syndrome patients. Children with concomitant HSCR and Down syndrome have a higher rate of postoperative complications and a longer hospital stay. During long-term follow-up most patients with Down syndrome are severely constipated and have a higher incidence of enterocolitis (73). Two of five of our patients with HSCR and Down syndrome had concomitant congenital hypothyroidism.

\section{Conclusion}

Approximately one third of all human congenital malformations are estimated to derive from the various segments of neural crest anomalies. The American pathologist Robert P. Bolande in 1974 coined the term neurocristopathies for various neurologic, endocrine, digestive, or other disorders arising from impaired growth, differentiation, or migration of neural crest cells (74). The neurocristopaties can represent an anomaly of simple organ, but also a vast range of diverse abnormalities combining anomalies of various organ systems derived from neural crest (75).

Hirschsprung disease, as a neurocristopathy, has a strong association with numerous congenital anomalies, syndromes and also functional abnormalities. In our group of patients the inci- dence of associated congenital anomalies was $26.1 \%$. But if we add also malfunctions (hypothyroidism, malfunction in cellular immunity, neurological deficit), the rate of patients with HSCR with additional defects achieves more than $50 \%$. Most of these anomalies are based on disrupted development, migration or differentiation of multipotent neural crest cells during embryogenesis. More than $10 \%$ of pediatric patients with HSCR has deficiency in cellular immunity or genitourinary abnormalities. The immune system malfunctioning may be related to disrupted development of the thymus, which depends also on neural crest cells. The genitourinary malformations in HSCR patients can be explained by genetic alterations of RET proto-oncogen, which plays a crucial role during the embryonic development of both, the enteric nervous system and kidney. An interesting finding is also that $7.6 \%$ of HSCR patients had concomitant congenital hypothyroidism, and $5.3 \%$ had concomitant congenital heart defect. Also the incidence of Down syndrome in HSCR patients is much higher, than in normal population. Our results show that Hirschsprung disease is not only a simple lack of neurons in distal part of gut, but the associated anomalies and malfunctions may affect numerous organs and may influence many physiological processes.

\section{References}

1. Kenny SE, Tam PK, Garcia-Barcelo M. Hirschsprung's disease. Semin Pediatr Surg 2010; 19: 194-200.

2. Newgreen D, Young HM. Enteric nervous system: development and developmental disturbances - part 1. Pediatr Dev Pathol 2002; 5: 224-247.

3. Feichter S, Meier-Ruge WA, Bruder E. The histopathology of gastrointestinal motility disorders in children. Semin Pediatr Surg 2009; 18: 206-211.

4. Newgreen D, Young HM. Enteric nervous system: development and developmental disturbances - part 2. Pediatr Dev Pathol 2002; 5: 329-349.

5. Bronner ME. Formation and migration of neural crest cells in the vertebrate embryo. Histochem Cell Biol 2012; 138: 179-186.

6. Bronner ME, LeDouarin NM. Development and evolution of the neural crest: an overview. Dev Biol 2012; 366: 2-9.

7. Vickaryous MK, Hall BK. Human cell type diversity, evolution, development, and classification with special reference to cells derived from the neural crest. Biol Rev Camb Philos Soc 2006; 81: 425-55.

8. Hall BK. The neural crest and neural crest cells: discovery and significance for theories of embryonic organization. J Biosci 2008; 33:781-93.

9. Kang P, Svoboda KK. Epithelial-mesenchymal transformation during craniofacial development. J Dent Res 2005; 84: 678-690.

10. Anderson RB, Newgreen DF, Young HM. Neural crest and the development of the enteric nervous system. Adv Exp Med Biol 2006; 589:181-196.

11. Ibarretxe G, Crende O, Aurrekoetxea M, García-Murga V, Etxaniz J, Unda F. Neural crest stem cells from dental tissues: a new hope for dental and neural regeneration. Stem Cells Int 2012; 2012: 103503.

12. Graham A, Richardson J. Developmental and evolutionary origins of the pharyngeal apparatus. Evodevo 2012; 3: 24.

13. Varga I, Pospisilova V, Gmitterova K, Galfiova P, Polak S, Galbavy S. The phylogenesis and ontogenesis of the human pharyngeal region focused on the thymus, parathyroid, and thyroid glands. Neuro Endocrinol Lett 2008; 29: 837-845. 
640-647

14. Sieber-Blum M. Cardiac neural crest stem cells. Anat Rec Part A 2004; 276A: 34-42.

15. Keyte A, Hutson MR. The neural crest in cardiac congenital anomalies. Differentiation 2012; 84: 25-40.

16. Hall BK. The neural crest as a fourth layer and vertebrates as quadroblastic not triploblastic. Evolution \& Development 2000; 2: 3-5.

17. Duhamel B. A new operation for the treatment of Hirschsprung's disease. Arch Dis Child 1960; 35: 38-39.

18. Ikeda K. New techniques in the surgical treatment of Hirschsprung's disease. Surgery 1967; 61: 503-505.

19. Soper RT, Miller FE. Modification of Duhamel procedure: elimination of rectal pouch and colorectal septum. J Pediatr Surg 1968; 3: 376-385.

20. Le Douarin NM, Teillet MA. The migration of neural crest cells to the wall of the digestive tract in avian embryo. J Embryol Exp Morphol 1973; 30: 31-48.

21. Fu M, Tam PK, Sham MH, Lui VC. Embryonic development of the ganglion plexuses and the concentric layer structure of human gut: a topographical study. Anat Embryol (Berl) 2004; 208: 33-41.

22. Wallace AS, Burns AJ. Development of the enteric nervous system, smooth muscle and interstitial cells of Cajal in the human gastrointestinal tract. Cell Tissue Res 2005; 319: 367-382.

23. Zábojníková L, Cingel V, Murgaš D, Fuňáková M, Sláviková T, Varga I. The development of enteric nervous system and pathogenesis of Hirschsprung disease. Česko-slov Pediatr 2012; 67: 402-409.

24. Skaba R. Historic milestones of Hirschsprung's disease (commemorating the $90^{\text {th }}$ anniversary of Professor Harald Hirschsprung's death). J Pediatr Surg 2007; 42: 249-251.

25. Heanue TA, Pachnis V. Enteric nervous system development and Hirschsprung's disease: advances in genetic and stem cell studies. Nat Rev Neurosci 2007; 8: 466-479.

26. Best KE, Addor MC, Arriola L, Balku E, Barisic I, Bianchi F, Calzolari E, Curran R, Doray B, Draper E, Garne E, Gatt M, Haeusler M, Bergman J, Khoshnood B, Klungsoyr K, Martos C, Materna-Kiryluk A, Matias Dias C, McDonnell B, Mullaney C, Nelen V, O'Mahony M, Queisser-Luft A, Randrianaivo H, Rissmann A, Rounding C, Sipek A, Thompson R, Tucker D, Wellesley D, Zymak-Zakutnia N, Rankin J. Hirschsprung's disease prevalence in Europe: a register based study. Birth Defects Res A Clin Mol Teratol 2014; 100(9): 695-702.

27. Li Y, Kido T, Garcia-Barcelo MM, Tam PK, Tabatabai ZL, Lau YF. SRY interference of normal regulation of the RET gene suggests a potential role of the Y-chromosome gene in sexual dimorphism in Hirschsprung disease. Hum Mol Genet. 2015; 24(3): 685-697.

28. Amiel J, Sproat-Emison E, Garcia-Barcelo M, Lantieri F, Burzynski G, Borrego S, Pelet A, Arnold S, Miao X, Griseri P, Brooks AS, Antinolo G, de Pontual L, Clement-Ziza M, Munnich A, Kashuk C, West K, Wong KK, Lyonnet S, Chakravarti A, Tam PK, Ceccherini I, Hofstra RM, Fernandez R; Hirschsprung Disease Consortium. Hirschsprung disease, associated syndromes and genetics: a review. J Med Genet 2008; 45: 1-14.

29. Moore SW, Zaahl MG. A review of genetic mutation in familial Hirschsprung's disease in South Africa: towards genetic counseling. J Pediatr Surg 2008; 43: 325-329.

30. Puri P, Shinkai T. Pathogenesis of Hirschsprung's disease and its variants: recent progress. Semin Pediatr Surg 2004; 13: 18-24.
31. Vaclavikova E, Kavalcova L, Skaba R, Dvorakova S, Macokova P, Rouskova B, Bendlova B. Hirschsprung's disease and medullary thyroid carcinoma: 15-year experience with molecular genetic screening of the RET proto-oncogene. Pediatr Surg Int 2012; 28: 123-128.

32. Moore SW. The contribution of associated congenital anomalies in understanding Hirschsprung's disease. Pediatr Surg Int 2006; 22: 305-315.

33. Kushch NL, Grona VN, Kimbarovskaia EM, Evseeva LI. Clinicoimmunologic comparisons of developmental defects of the large intestine in children. Klin Khir 1988; 6: 10-12.

34. Niederreither K, Vermot J, Le Roux I, Schuhbaur B, Chambon P, Dollé $\mathbf{P}$. The regional pattern of retinoic acid synthesis by RALDH2 is essential for the development of posterior pharyngeal arches and the enteric nervous system. Development 2003; 130(11): 2525-2534.

35. Foster K, Sheridan J, Veiga-Fernandes H, Roderick K, Pachnis V, Adams R, Blackburn C, Kioussis D, Coles M. Contribution of neural crest-derived cells in the embryonic and adult thymus. J Immunol 2008; 180: 3183-3189.

36. Hacsek G, Ormälä T, Rintala R, Savilahti E. B-cell development in lamina propria of the large intestine: influence of age and T-cell densities. APMIS 1999; 107: 661-666.

37. Jijiwa M, Fukuda T, Kawai K, Nakamura A, Kurokawa K, Murakumo Y, Ichihara M, Takahashi M. A targeting mutation of tyrosine 1062 in Ret causes a marked decrease of enteric neurons and renal hypoplasia. Mol Cell Biol 2004; 24: 8026-8036.

38. Chi X, Michos O. Immunohistochemical staining of dpERK staining during early kidney development. Methods Mol Biol 2012; 886: 261-265.

39. Godbole K. Many faces of Hirschsprung's disease. Indian Pediatr 2004; 41: 1115-1123.

40. Skinner MA, Safford SD, Reeves JG, Jackson ME, Freemerman AJ. Renal aplasia in humans is associated with RET mutations. Am J Hum Genet 2008; 82: 344-351.

41. Moore SW, Tshifularo N. Hirschsprung's disease in the neurologically challenged child. Int J Adolesc Med Health 2011; 23: 223-227.

42. Shahar E, Shinawi M. Neurocristopathies presenting with neurologic abnormalities associated with Hirschsprung's disease. Pediatr Neurol 2003; 28: 385-391.

43. Baranyay F, Bogár G, Sebestyén M. Adult Hirschsprung’s disease with mental retardation and microcephaly. Orv Hetil 2000; 141: 1673-1676.

44. Sarioglu A, Tanyel FC, Büyükpamukçu N, Hiçsönmez A. Hirschsprung-associated congenital anomalies. Eur J Pediatr Surg 1997; 7: $331-337$.

45. Baltogiannis N, Mavridis G, Soutis M, Keramidas D. Currarino triad associated with Hirschsprung's disease. J Pediatr Surg 2003; 38: 1086-1089.

46. Kilickesmez O, Gol IH, Uzun M, Oruk C. Complete familial Currarino triad in association with Hirschsprung's disease: magnetic resonance imaging features and the spectrum of anorectal malformations. Acta Radiol 2006; 47: 422-426.

47. Alkuraya FS, Lin AE, Irons MB, Kimonis VE. Fryns syndrome with Hirschsprung disease: support for possible neural crest involvement. Am J Med Genet A 2005; 132A: 226-230.

48. Goldenberg A, Milh $M$, de Lagausie $P$, Mesnage $R$, Benarif $F$, de Blois MC, Munnich A, Lyonnet S, Cormier-Daire V. Werner mesomelic dysplasia with Hirschsprung disease. Am J Med Genet A 2003; 123A: 186-189. 
49. Mustafin AA, Sultanova LM. Differential diagnosis of Hirschsprung's disease and congenital hypothyroidism in children. Vestn Khir Im I I Grek 1985; 134: 89-91.

50. Goto S, Billmire DF, Grosfeld JL. Hypothyroidism impairs colonic motility and function. An experimental study in the rat. Eur J Pediatr Surg 1992; 2:16-21.

51. Kota SK, Modi KD, Rao MM. Hirschsprungs disease with congenital hypothyroidism. Indian Pediatr 2012; 49: 245-246.

52. Eren M, Celik M, Kinik S, Arda IS. A case of Hirschsprung disease: does thyroid hormone have any effect? Turk J Pediatr 2009; 51: 94-96.

53. Monroy-Santoyo S, Ibarra-González I, Fernández-Lainez $C$, Greenawalt-Rodríguez S, Chacón-Rey J, Calzada-León R, Vela-Amieva M. Higher incidence of thyroid agenesis in Mexican newborns with congenital hypothyroidism associated with birth defects. Early Hum Dev 2012; 88: 61-64.

54. Manley NR, Capecchi MR. Hox group 3 paralogs regulate the development and migration of the thymus, thyroid, and parathyroid glands. Dev Biol 1998; 195: 1-15.

55. Wetherill C, Sutcliffe J. Hirschsprung disease and anorectal malformation. Early Hum Dev 2014; 90(12): 927-932.

56. Han-Geurts IJ, Hendrix VC, de Blaauw I, Wijnen MH, van Heurn EL. Outcome after anal intrasphincteric Botox injection in children with surgically treated Hirschsprung disease. J Pediatr Gastroenterol Nutr 2014; 59(5): 604-607.

57. Pierpont MEM, Gobel JW, Moller JH, Edwards JE. Cardiac malformations in relatives of children with truncus arteriosus or interruption of the aortic arch. Am J Cardiol 1988; 61: 423-427.

58. Jenkins KJ, Correa A, Feinstein JA, Botto L, Britt AE, Daniels SR, Elixson M, Warnes CA, Webb CL. Noninherited risk factors and congenital cardiovascular defects: current knowledge: a scientific statement from the American Heart Association Council on Cardiovascular Disease in the Young: endorsed by the American Academy of Pediatrics. Circulation 2007; 115: 2995-3014.

59. Spouge D, Baird PA. Hirschsprung disease in a large birth cohort. Teratology 1985; 32: 171-177.

60. Tuo G, Pini Prato A, Derchi M, Mosconi M, Mattioli G, Marasini M. Hirschsprung's disease and associated congenital heart defects: A prospective observational study from a single institution. Front Pediatr 2014; 2: 99.

61. Kirby ML, Gale TF, Stewart DE. Neural crest cells contribute to aorticopulmonary septation. Science 1983; 220: 1059-1061.
62. Kirby ML, Waldo KL. Neural crest and cardiovascular pattering. Circ Res 1995; 77: 211-215.

63. Pelech AN, Broeckel U. Toward to etiologies of congenital heart disease. Clin Perinatol 2005; 32: 825-844.

64. Hutson MR, Kirby ML. Model systems for the study of heart development and disease. Cardiac neural crest and conotruncal malformations. Semin Cell Dev Biol 2007; 18: 101-110.

65. Moore SW, Rode H, Millar AJ, Albertyn R, Cywes S. Familial aspects of Hirschsprung's disease. Eur J Pediatr Surg 1991; 1: 97-101.

66. Bergstrom CS, Saunders RA, Hutchinson AK, Lambert SR. Iris hypoplasia and aorticopulmonary septal defect: a neurocristopathy. J AAPOS 2005; 9: 264-267.

67. Nagaya M, Kato J, Niimi N, Tanaka S, Wakamatsu N. Clinical features of a form of Hirschsprung's disease caused by a novel genetic abnormality. J Pediatr Surg 2002; 37: 1117-1122.

68. el-Halaby E, Coran AG. Hirschsprung's disease associated with Ondine's curse: report of three cases and review of the literature. J Pediatr Surg 1994; 29: 530-535.

69. Skiker H, Laghmari M, Cherkaoui O, Lachgar R, Daoudi R. Bilateral Duane syndrome associated with crocodile tears, and congenital megacolon: a case study. J Fr Ophtalmol 2008; 31: e6.

70. Farlie PG, McKeown SJ, Newgreen DF. The neural crest: basic biology and clinical relationships in the craniofacial and enteric nervous systems. Birth Defects Res C Embryo Today 2004; 72: 173-189.

71. Amiel J, Lyonnet S. Hirschsprung disease, associated syndromes, and genetics: a review. J Med Genet 2001; 38: 729-739.

72. Arnold S, Pelet A, Amiel J, Borrego S, Hofstra R, Tam P, Ceccherini I, Lyonnet S, Sherman S, Chakravarti A. Interaction between a chromosome 10 RET enhancer and chromosome 21 in the Down syndrome-Hirschsprung disease association. Hum Mutat 2009; 30: 771-775.

73. Travassos D, van Herwaarden-Lindeboom M, van der Zee DC. Hirschsprung's disease in children with Down syndrome: a comparative study. Eur J Pediatr Surg 2011; 21: 220-223.

74. Bolande RP. Neurocristopathy: its growth and development in 20 years. Pediatr Pathol Lab Med 1997; 17: 1-25.

75. Zhang D, Ighaniyan S, Stathopoulos L, Rollo B, Landman K, Hutson J, Newgreen D. The neural crest: a versatile organ system. Birth Defects Res C Embryo Today 2014; 102(3): 275-298.

Received January 6, 2015. Accepted June 26, 2015. 